\title{
UNIVERSITYOF
}

FORWARD

THINKING

WESTMINSTER用

WestminsterResearch

http://www.westminster.ac.uk/westminsterresearch

\section{In one's own time: Contesting the temporality and linearity of bereavement}

Kenny, K., Broom, A., Kirby, E. and Ridge, Damien T.

This is a copy of the accepted author manuscript of the following article: Kenny, K., Broom, A., Kirby, E. and Ridge, Damien T. (2017) In one's own time: Contesting the temporality and linearity of bereavement, Health: An Interdisciplinary Journal for the Social Study of Health, Illness and Medicine. DOI: 10.1177/1363459317724854. The final definitive version is available from the publisher Sage at:

https://dx.doi.org/10.1177/1363459317724854

(C) The Author(s) 2017

The WestminsterResearch online digital archive at the University of Westminster aims to make the research output of the University available to a wider audience. Copyright and Moral Rights remain with the authors and/or copyright owners.

Whilst further distribution of specific materials from within this archive is forbidden, you may freely distribute the URL of WestminsterResearch: ((http://westminsterresearch.wmin.ac.uk/)).

In case of abuse or copyright appearing without permission e-mail repository@westminster.ac.uk 
Title: In one's own time: Contesting the temporality and linearity of bereavement

\section{Author Affiliations:}

1. Dr Katherine Kenny

Practical Justice Initiative

Level 3, Goodsell Building

University of New South Wales

Sydney, NSW 2052

Australia

Ph: +61 293858127

Email: katherine.kenny@unsw.edu.au

2. Professor Alex Broom

Practical Justice Initiative

Level 3, Goodsell Building

University of New South Wales

Sydney, NSW 2052

Australia

Ph: + 61293852829

Email: a.broom@unsw.edu.au

\section{Dr Emma Kirby}

Practical Justice Initiative

Level 3, Goodsell Building

University of New South Wales

Sydney, NSW 2052

Australia

Ph: + 61293859065

Email: Emma.kirby@unsw.edu.au

4. Professor Damien Ridge

Department of Psychology

115 New Cavendish Street

London W1W 6UW

United Kingdom

Ph: + 442079115000 ext 64154

Email: D.Ridge@westminster.ac.uk 


\section{Author Bios}

Katherine Kenny is a Postdoctoral Research Fellow in Sociology in the Practical Justice Initiative at the University of New South Wales, Sydney Australia. She brings together disciplinary training in sociology and science and technology studies and uses a range of qualitative methods to explore the intersection of the politics of knowledge production with lived experiences of health and illness. She is currently working on a project investigating the social meanings of cancer survivorship for patients, their carers and health professionals.

Alex Broom is Professor of Sociology and Co-director of the Practical Justice Initiative at the University of New South Wales, Sydney, Australia. He specializes in the sociology of health and illness; cancer; palliative and end-of-life care; death, dying and bereavement; traditional, complementary and alternative medicines; social inequalities and social justice; and, health in developing countries. Recent books include 'Evidence-based healthcare in context' (Ashgate, 2012), 'Gender and Masculinities: Histories, Texts and Practices in India and Sri Lanka' (Routledge, 2013), 'Dying: A Social Perspective on the End of Life' (Ashgate, 2015) and Bodies and Suffering: Emotions and Relations of Care (Routledge, 2017).

Emma Kirby is UNSW Scientia Fellow, Australian Research Council DECRA Fellow, and Senior Research Fellow in the School of Social Sciences at the University of New South Wales, Sydney, Australia. She focuses on experiences of end-of-life and palliative care, women's health, and interpersonal relationships in health care. Drawing on the sociology of health, family and relationships, her work reveals how social interactions shape care and support during illness. Her current research will offer policy and practice-relevant data to improve our understanding of the role and significance of informal care in end of life contexts.

Damien Ridge is Professor of Health Studies and Head of Psychology at the University of Westminster, London. Committed to putting patient experience at the heart of health considerations, he combines university-based research with work as a psychotherapist in the community. Drawing on his background in the social sciences and narrative research, his key areas of study include depression, mental health, men's wellbeing, chronic health conditions, HIV and sexuality. He has authored over 70 peer-reviewed academic publications and been funded by bodies including the MRC/ESRC, NIHR, NHS, Wellcome Trust, Make My Day Better (MMDB), and the Quintin Hogg Trust (QHT).

This article version may not exactly replicate the final version published in Health. It is not the copy of record. 
Title: In one's own time: Contesting the temporality and linearity of bereavement

\section{Abstract (154 words):}

This article explores the experience and meaning of time from the perspective of caregivers who have recently been bereaved following the death of a family member. The study is situated within the broader cultural tendency to understand bereavement within the logic of stages, including the perception of bereavement as a somewhat predictable and certainly time-delimited ascent from a nadir in death to a "new normal' once loss is accepted. Drawing on qualitative data from interviews with 15 bereaved family caregivers we challenge bereavement as a linear, temporally-bound process, examining the multiple ways bereavement is experienced and how it variously resists ideas about the timeliness, desirability and even possibility of 'recovery'. We posit, on the basis of these accounts, that the lived experience of bereavement offers considerable challenges to normative understandings of the social ties between the living and the dead, and requires a broader reconceptualization of bereavement as an enduring affective state.

\section{Keywords:}

Bereavement, death, dying, temporality, recovery

\section{Introduction}

Since the late 1960s, scholars have pushed for the development of higher levels of support for the affective dimensions of death and dying (Saunders, 1978; KüblerRoss, 1969). The modern hospice movement was particularly influential, both in clinical practice and the cultural imaginary. Here, for example, British physician Dame Cicely Saunders introduced the idea of 'total pain' to account for the 
psychological, social, emotional and spiritual dimensions of distress that accompanied the physical processes of dying (Saunders, 1978). Similarly, SwissAmerican psychiatrist Elisabeth Kübler-Ross postulated a series of emotional stages denial, anger, bargaining, depression, and (eventual) acceptance - in response to loss in her seminal contribution On Death and Dying (1969; see also Bowlby, 1961; Clark, 2000; Parkes, 1972). While Kübler-Ross herself intended the notion of stages as a useful heuristic, not a reified model, the presence of such staged approaches to grief within the spheres of death, dying and bereavement remains pervasive. Contemporary psycho-therapeutic approaches encompass considerable variation and nuance across different theoretical perspectives on bereavement-related grief (see Stroebe et al., 2008; Klass et al., 2014), and recent empirical studies have drawn contradictory conclusions regarding the empirical adequacy of the stages model across many spheres of grief and loss (Holland and Neimeyer, 2010; Maciejewski et al., 2007). There is a general recognition within the scholarly literature that grief in bereavement must be understood as highly complex: there are multiple trajectories through (and potential disruptions and stagnations within) grief and many bereaved individuals maintain various forms of ongoing relations with the deceased.

Despite the scholarly push to move beyond a stages model in considering the dynamics of bereavement (e.g. Hall, 2014; Stroebe et al., 2008), the notion of bereavement as itself a stage (of sorts) continues to have considerable lay and clinical traction and heavily influences cultural ideas surrounding bereavement. As most bereavement care and support is informal - offered by family and friends outside of medical settings - lay logics are particularly important for understanding the landscapes and lived experiences of bereavement. In this sense, bereavement - the 
experience following the death of someone to whom we are related and/or close exists at the nexus of professional and lay realms; influenced, as it were, concurrently by lay and professional ideas about the legitimacy of grief and the eventual accomplishment of 'recovery'. This is not to suggest that models of the 'typical' course of human emotions in bereavement do not have productive facets: models of the expected trajectory of grief and recovery can (when used judiciously) help people feel less alone and normalise the range of emotions experienced by family, carers and health professionals of those who have died (Hall, 2014). Similarly such models may help muster resources and encourage policy makers and care providers to offer specific support. But, as with various other process of normalisation (Foucault, 1977: 184) standardising and codifying grief (Stroebe and Schut, 2001), can also be constraining in terms of the individual and collective expression of grief and mourning. Whereas typical experiences (and normative constructs) may be legitimised through such models, others that fall outside the normal range can then appear to be unusual,_deviant or even pathological (see Bandini, 2015; Pies, 2014; Rosenblat, 2007). Thus, cultural configurations of bereavement powerfully shape what bereavement can and should be, and how individuals understand their own experiences of loss vis-à-vis such expectations.

Here we argue that the lived experience of bereavement is still heavily embedded in enduring cultural logics of staged and time-limited grief; and that this offers considerable challenge to the bereaved. In particular, bereavement is often understood as a simple ascension from an affective low accompanying death, to a 'new normal' once the loss has been experienced, processed and eventually 'accepted'. Importantly, the expectation of an eventual recovery from loss, or the return to normalcy, hinges 
upon the timely relinquishing of affective ties with the deceased and a reorientation of one's social life - and the social ties therein - towards the sphere of the living (Seale, 1998. See also Howarth, 1997: 197). In this paper, we problematize this reading and treatment of bereavement along the axis of time and explore how temporal considerations shape what is allowed, considered normal, and how people $d o$ bereavement. Time-based logics and assumptions about what form recovery should take, can be both a cultural resource and a normative pressure and require greater critical sociological exploration than has hitherto been the case. In this study, we found that the experience of temporality in bereavement challenges cultural expectations around a staged approached to grief and ideas around bereavement as, itself, a stage. We argue that the experience of bereavement is characterised instead by a set of affective tensions around the timeliness (and timelessness) of death, the enduring nature of social bonds beyond death, and cultural expectations regarding the pace of 'moving on'.

\section{Time in social life and death}

Considerations of time have a long-standing place in social theory (Adam, 1990), where it has been theorized as central to human meaning-making practices (Ricoeur, 1984), and as a key organizing principle of the life course, including enduring relationships, family formation and work (Mills, 2000; Thompson, 1967; Perlow, 1999; Epstein and Kalleberg, 2001). Time features prominently in theoretical understandings of individuals' constructions of self-identity (Giddens, 1991; McAdams, 2006), and efforts at life-planning or attempts to 'colonize the future' under the conditions of ontological in/security in late modernity (Giddens, 1991; see also Nowotny, 1994). Similarly, time has been a long-standing concern of scholars of 
death, dying and bereavement (Faunce and Fulton, 1958; Glaser and Strauss, 1965, 1968. See also Kellehear, 2007). For example, Glaser and Strauss (1965, 1968) argued for the reconceptualisation of death as a temporal process located within social time rather than as singular event within an individual's biological life/time. While understandings around death, dying and bereavement vary enormously across (and even within) different cultures, our analysis will emphasize that all experiences of death, grief and bereavement are interwoven with the cultural context in which they occur and the cultural practices through which they are made meaningful (Walter, 1995, 1999; Einsebruch, 1984; Parkes et al., 2015). Central to these, we argue, are social expectations and individual experiences around time. Within contemporary Western contexts, cultural understandings of grief and bereavement are often embedded in a time-limited logic of loss, grief and suffering (Neimeyer et al., 2002), with considerations of both temporality and notions of justice in death and dying shaping expectations around bereavement. Here, untimely deaths (cf. Parry, 1994), sudden or unexpected deaths, the deaths of children and so on, variously provoke a sense of injustice at 'time taken away' and can conflict with social expectations surrounding the 'good death' as it is normatively construed (Author, 2016). Similar considerations also shape the experience, dynamics and normative constructs surrounding bereavement, configuring the respective landscape of individual and collective grieving in ways that are also linked to time: that death 'came too soon', someone 'died too young', or even that 'they suffered too long'. Time is thus central to our sense-making around death with varying consequences for how individuals experience and enact bereavement, and how others judge their process. 
Despite considerable cross-cultural variation in social expectations surrounding death and the experience of bereavement (e.g. Parkes et al., 2015; Rosenblatt, 2008; Stroebe and Schut, 1998) in contemporary Western contexts, bereavement is largely (if only implicitly) bracketed as a period of 'time out' of normal social life. ${ }^{1}$ The bereavement period, as it were, thus becomes a relatively brief segment of emotional processing and eventual acceptance, followed by a timely re-entering into society and 'normal' life. This view is articulated in various grief-related cultural maxims: in dealing with loss 'in one's own time', as 'a process', 'working through it', and eventually, 'moving on'3. The temporal dynamics in and around bereavement are reminiscent of the Parsonsonian sick role (Parsons, 1975) - that the bereaved will not be able to function normally for a period of time, will need various forms of support, and will not be able to perform their normal social role as a worker, mother, etc. for a certain period of time. While a precise timeframe may or may not be specified, the logic holds that this window of time will draw to a close once the bereaved processes their loss and eventually moves on towards their new normal (Gillies and Niemeyer, 2006).

Just as with the Parsonian sick role, the assumed temporary nature of the bereavement phrase predicates permission to grieve upon the assumption of a timely recovery, i.e. recovery is a condition of being allowed to take on the bereaved role (Parsons, 1975). And, as with the Parsonian analysis, by containing the role we also define what is acceptable, and thus where deviance lies. In bereavement, as we will show in the results below, such things as 'holding on' or 'not letting go' thereby become forms of deviance and even psychopathology (Horowitz et al., 2003). This poses considerable problems for the lived experience of bereavement when death may actually be 
experienced through such notions as timelessness, the continuity of personhood, or presence beyond death (See Rosenblatt, 2008; Parkes et al., 2015).

\section{Outside of time: towards enduring affective relations}

Here we posit that cultural logics around the staged approaches to grief and bereavement as a temporary, individual affective state that can (and should) be bracketed, supported and/or treated and, ultimately, moved on from, are problematic. As with death, Western understandings of bereavement can be characterized as public medicalisation and private individualisation (Charmaz and Milligan, 2006), with limited public opportunities for on-going relationality with the dead. A key assumption is the reintegration logic - that the bereaved ultimately give up their relationship with the deceased and reorientate their social ties towards the sphere of living (Howarth, 2007: 197). Bereavement becomes a (temporality limited) liminal space in which the deceased is afforded a temporary on-going social presence. This enforces the cultural demarcation between the spheres of the living and the dead and, conversely, the temporal circumscription of bereavement becomes necessary to uphold the cultural separation between life and death. Put differently, the temporality of bereavement is culturally enforced in order to maintain the orientation of the living towards life and away from death. This is the production of a functional citizenry, and relates back to the social contract around bereavement as a 'time out', but one that gives way to a timely recovery. In our focus on the temporality of bereavement, then, we offer an extension on existing sociological perspectives that highlight how emotions such as grief are both socially shaped and culturally configured, and how they provide an affective window into the meanings of social attachments (Lofland, 1985; Charmaz and Milligan, 2006; Seale, 1998). We show that the experiences of 
many bereaved family caregivers sit in tension with the cultural logics around bereavement as a stage, which requires the relinquishing of social ties with the deceased and the accomplishment of timely moving on. We show, instead, how their experiences of bereavement are characterised by a set of affective tensions, which centre around issues of time.

\section{Methods:}

This paper draws on 15 semi-structured interviews that were conducted with bereaved Australian family caregivers. We use the term 'family caregiver' or simply 'carer', to describe any kin or non-kin relative, friend, or person with a significant relationship to the deceased person, and to whom they provided support or assistance approaching the end of life (Hudson and Payne 2009). These interviews were carried out as the final phase of a broader study into patient and caregiver experiences of palliative care $^{2}$ (Broom et al., 2016; MacArtney et al., 2017; MacArtney et al., 2016; MacArtney et al., 2015). Given the sensitive topic of research, face-to-face interviews were employed as an effective and empathic method for documenting experiences of death, dying and (later) bereavement. After we obtained both university and hospital ethics approval, patients and carers were approached by their treating clinician, who explained the study aims and methods of data collection. Researchers were then provided with the contact details of interested parties, who were contacted to confirm participation, arrange an initial interview, and obtain formal written consent. Initial interviews sought to explore experiences of specialist palliative care, including reflections on the patient's illness and time before admission, perspectives on the transition to palliative care, and the impacts of the dying process on family/carers. At the end of initial interviews, carers were asked if they would be interested in a follow- 
up interview after the the family member had died. Around 6 months after the initial interviews, carers were contacted again to reconfirm their desired participation, and, if appropriate, arrange a final (follow-up) interview. Of the original 67 family caregivers we interviewed, 48 volunteered to be contacted for a follow-up interview. We were able to contact 21 of these caregivers, 2 of whom had moved away from the area and 4 of whom declined to be interviewed. The remaining 15 informal carers participated in follow-up interviews, including 1 husband, 4 wives, 5 daughters, 4 sons, and 1 granddaughter. Interviews sought to explore carers' experiences of the death of their family member, the transition beyond palliative care, reflections on any formal/informal support that was offered and reasons for accepting or declining such support, and their reflection on bereavement thus far. Interviews were conducted at a place of mutual convenience - most often the carer's residence, lasted between 20 and 60 minutes, were digitally recorded and transcribed in full. Participants' direct quotes are identified here using pseudonyms, their age bracket, their relationship to the deceased and the age bracket within which their family member died.

\section{Analysis}

The methodology for this project draws on the interpretive traditions in sociology, especially on Charmaz's approach to social analysis (1990). The aim was to achieve a detailed understanding of the participants' responses and to locate them within a broader context of underlying beliefs, agendas and life experiences. The approach to data collection was developmental; knowledge generated in early interviews was challenged, compared with, and built upon by later insights and experiences. This method enabled us to develop our analysis iteratively with data collection. We established initial themes and then sought out counter examples and/or negative 
cases. We approached the analysis of the interviews thematically, systematically reviewing interview transcripts both individually and as a team, discussing emerging ideas with colleagues and frequently revisiting the data and revising our analyses in light of new data collected. Throughout we sought to retain the richness of the participants' experiences, documenting atypical cases, conflicts, and contradictions within the data. Finally, we revisited the literature and sought out conceptual tools that could be employed to make sense of the themes that had emerged from the data.

\section{Findings}

Throughout our interviews, participants recounted their experiences of affective and temporal tensions clustered around how to manage their time and their emotions following the death of someone they had cared for. These were expressed around a number of themes: around allocating time for the logistical tasks following death, around the timeframes for appropriate grieving and around the timeliness of the death, itself. In these themes we identify a set struggles around affective 'holding on', practical 'getting on with it' and cultural pressures to accomplish timely 'moving on'.

\section{Managing time after death: 'Doing' and 'reflecting'}

Each of our participants described temporal tensions following the death of their family member, which ranged from juggling administrative and logistical tasks (especially for those still in the workforce) to managing having 'too much time' (especially for those who previously provided high levels of care for their family member). For many, this involved difficulties in deciding how to manage their time often characterized as, on the one hand keeping busy and, on the other, allowing time for reflection. Time for reflection was seen as necessary, but was also carefully 
circumscribed: too much time reflecting was seen as wallowing or dwelling and as a failure to move on within the normatively prescribed timeframe. However, balancing keeping busy with reflecting on the loss was experienced as a tension and participants often made contradictory claims about the two imperatives over the course of a single interview. One participant described life since the death of his spouse, emphasizing that moving on and not dwelling on the loss was a good thing:

Things have just ground on... we're settling down. My family's settled down, accepted what's happened, and we live on. We manage... Life moves on ... You've got to move on as best you can...Really, I haven't got time to dwell and sit about. It's probably a good thing.

However, when asked for clarification about a lack of time to dwell being a good thing, he equivocated:

From time to time, I wish I could get a day off and get away from it all... It is good to just reflect from time to time, sit and enjoy the view. [Gordon, aged 80-89, carer to his wife, aged 70-79]

For some, this tension was particularly acute immediately following the death due to the administrative and logistical tasks required to organise funerals, deal with wills and estates and often, selling the deceased's home. The busyness of the first few months often precluded time for reflection: 
The first, I'd say the first couple of months, there was so much going on. The realisation of what's actually happened doesn't hit you, and it's after that and you stop and think, "Oh... I'm never ever going to see that person again.” [Sarah, aged 50-59, carer to her husband, aged 60-69]

For many of the participants, this was seen in a positive light:

I'm a doer. I've got to be doing things. I'm not very good at just sitting around analysing... I don't know. I mean if [the death] was something that was very sudden or it was an act of terror, yes, but we had a long time, this dragged on over eight months. So it just wasn't something that I was interested in doing. [Barbara, aged 40-49, carer to her mother, aged 80-89]

Conversely, and particularly for bereaved carers who had previously provided high levels of care, the absence of their former caring duties left a void in their lives. The same participant above, whose work schedule was determine on an annual basis, explained how the requirements of caring for her mother meant she didn't increase her work load for the coming year - leaving her with 'too much time on her hands' after her mother died:

I try to keep myself as busy as possible [but] I had cut down quite a lot on work last year so that I could look after mum... She didn't die until February, so I didn't increase hours... I'm not good with too much time on 
my hands. So Mondays and Tuesdays have been really big voids. [Barbara, aged 40-49, carer to her mother, aged 80-89]

Another carer experienced the end of their caring duties as a loss in addition to the loss of the deceased:

[A]ll the things you were doing beforehand while mum was sick, while I was looking after her and things like that, you're not doing them anymore and sort of, that leaves a big hole as well, as well as missing the person, you know? [Susan, aged 60-69, carer to her mother, aged 80-89]

Importantly, keeping busy was normatively tied to moving on, which was described in spatial as well as temporal terms, i.e. as moving forward or as keeping going:

It is very little steps and it will be little steps for a while, I'm sure of that. I thought I'd be able to stride forward, but it's not that way at all. [Barbara, aged 40-49, carer to her mother, aged 80-89]

[Patient's name] wanted me to move forward, so I didn't go down... my thoughts are, you either sink or you swim, so I kept swimming. Yeah, I handled everything okay... as I keep on saying, I can't let [him] down [Sarah, aged 50-59, carer to her husband, aged 60-69]

The normative element of moving on is here expressed in concrete individual terms, as not 'letting down' the deceased. But it was also expressed in more amorphous 
terms - as enacting cultural scripts around appropriate bereavement, adequate 'coping' and timely moving on. One bereaved carer recounted:

I basically sat there and did absolutely nothing for about three to four to five months and just pretended [the deceased's estate] wasn't really there, it wasn't really happening... I wasn't wallowing but I wasn't really moving forward... So basically, my husband, who's not normally pushy just ended up saying, "You're going to have to start taking some definitive action and do something... You just need to start moving and doing something and then you'll start coping a lot better". And he was absolutely right. [Barbara, aged 40-49, carer to her mother, aged 80-89]

In this account, wallowing is seen in a negative light and as antithetical to 'moving forward' - something the respondent feels she did not accomplish until 'pushed' to do so by her husband.

Other participants expressed a greater degree of uncertainty about the appropriateness of their emotional experiences of bereavement.

[T]here are these periods which come, which are sort of (laughs) they're sort of so intense that I don't wanna have them...Because when, I know, you know from experience, that if you start that sort of thinking you, you start spiraling, start spiraling down and I don't... it's just, it's just... I don't quite know whether it's a good thing to do or not. No one's told me that, but, like whether I should sort of wallow in it and kind of enjoy it in 
some way, even, you know, even though it's painful. Or, sorta should I block it out all the time... I suppose it's not good for you to block it out all the time, you have to sort of acknowledge, that your mum's died ten months ago now. [Steven, aged 50-59, carer to his mother, aged 90-99]

This uncertainty around appropriate grieving i.e. whether to wallow in or block out emotions, highlights the cultural silences around death and bereavement - and the bracketing of death more generally. Here, normative concerns about appropriate grieving are intertwined with practical concerns about how to do grieving, at all. At both of these registers, the tension captured by this sentiment speaks to broad cultural silences around of grieving - what it consists of and how it is supposed to be done in the wake of bereavement.

\section{In one's own time: individual vs culturally prescribed grieving}

Any notion of 'appropriate' coping depends, fundamentally, on how bereavement is configured in the cultural imaginary. As discussed above, bereavement, at least in contemporary Western contexts, is normatively construed as a time delimited recovery from loss with an emphasis on a timely progression through a series of stages towards an endpoint involving 'acceptance', 'recovery' and 'moving on'. However, many of the participants encountered friction between this cultural construction of bereavement and their own experience of loss and grief, with temporal aspects featuring prominently in participants' reflections. These tensions were expressed in a number of ways; as confusion about cultural expectations, uncertainty about culturally defined appropriate timeframes, ambivalence about 
holding on vs. moving on, and as a sense of failure, anger or frustration at interpersonal/cultural expectations of the bereaved.

It is not only a matter of participants internalising societal timeframes for grieving, they also understandably craved an ending to their own suffering, and some indication of their own progress towards recovery. But some also rejected normative timeframes for their own processes, as one respondent remarked:

I let myself think of different things to a certain extent and I stop myself thinking about other things because I know, [deep breath] you know that if I get upset, break down or whatever, I'm not gonna be able to cope so... I just think it's you know, I just, I don't think there's a time limit on anything like that [Susan, aged 60-69, carer to her mother, aged 80-89]

While rejecting a specific time limit for grief, per se, this respondent also demonstrates the affective weight of cultural scripts around adequate coping in their reflections on avoiding getting upset or 'breaking down' - both of which are seen as inadequate coping. Such practices of self-discipline also had a temporal element:

[S]omebody said to me, “Just take your time, you don't have to be up and chirpy straightaway, if it takes months...." One of my good friends said it took her five years to kind of just feel normal, any way normal again. [Lisa, aged 50-59, carer to her husband, aged 70-79] 
Although this friend is implicitly giving the respondent permission to 'take their time', the assumption is still that there will be a return to being 'up and chirpy'- a recovery somewhere set in the future. The bereaved is given permission to deviate from their normal social role with the proviso that they will return to it at some point in the future. The implication is that bereavement is imagined to be a temporary affective state that is resolved with time.

While the above participants embraced quite flexible timeframes, many adopted 12 months as a meaningful benchmark tied to notions of progress in moving on:

So we're on the mend, I guess, to a degree. I'm sure the first 12 months is the worst. It will be the first of everything. But we'll be okay. We've got each other and we know who our friends are so we're fine, I guess. [Beth, aged 50-59, carer to her husband, aged 50-59]

We got through the first year so it probably doesn't get much better though. [Barbara, aged 40-49, carer to her mother, aged 80-89]

Even though each of these participants uses 12-months as a meaningful milestone, they also allow some degree of doubt and ambivalence about this temporality; their comments are provisional, subject to revision in light of emerging experience. A similar lack of trust in a grieving trajectory was more explicitly questioned by one participant: 
They (the children) still struggle because it's still very fresh, it's still very raw and I'm supposing that it will get better for them, but I don't know what an appropriate timeframe is. [Beth, aged 50-59, carer to her husband, aged 50-59]

While the timeframe for appropriate grieving is questioned, the underlying assumption that 'it will get better' as the bereaved move on is more strongly endorsed by our participants. This assumption is not unique to any single respondent, and instead appears to be part of a common cultural imaginary about appropriate grieving during bereavement. It serves to frame and configure the expectations and allowances afforded to the bereaved. Many of our participants experienced tensions between these social expectations and their own experience of loss and grief, often resulting in feelings of frustration and anger. These participants describe remaining in relationship to the deceased, and a sense of being left behind by their social networks, who did not:

I just find it really frustrating and I do get quite angry and upset sometimes. I know that life goes on. I'd be talking to girlfriends and stuff like that and it's like they've forgotten that I've lost my husband. They haven't, but nothing really changed in their life. But for me, and my family, it has. I find that's difficult sometimes. You know that life goes on and you are getting on with yours, but other people seem to move ahead more quickly with their life than the people who have actually been affected [and] have actually lost their loved one. [Beth, aged 50-59, carer to her husband, aged 50-59] 
Similarly,

And what I did find, is most times, these days, it's clichés from other people that's, "Oh, you can put it all behind you now and move on." Oh God, I hate those clichés. I think, explain to me how exactly do you do that, you know? It's not exactly like the dog died. It's your parents. It's such a visceral thing you know? You can't just say, (exhales) "that's done, let's move on." [Jan, aged 50-59, carer to her parents aged 90-99]

The tension between social expectations of the bereaved and these carers' individual experience of grief and loss was a source of misunderstanding, frustration and even anger. The expectation that 'life goes on', somehow, without the deceased, created hardship for some participants who felt left behind with their (deceased) loved ones. The practicalities of how that happens, of how life goes on, also created an enduring sense of questioning amongst participants, further compounding their experience of uncertainty and, often, frustration in relation to bereavement.

Similar misunderstandings and frustrations were encountered, albeit less commonly, when the death of a family member brought release and/or relief. One bereaved carer recounted her experience following the death of her mother, with whom she had a strained and difficult relationship. Her experience is at odds with the cultural script of caring motherhood, and so is a particularly taboo topic, producing a particular type of distress for her:

And yet, it goes against everyone's expectations. I know with mum, I keep getting this, "Ah your mum..." you know. And I felt such a bloody 
hypocrite, you know. Oh, you know, "Oh, you've lost your mum," and I think, (crying) "It doesn't mean anything to me." She was horrible. She died horrible. ... Cause it just flies on the face of everyone's expectations, and everything. Everyone takes for granted some sort of loving relationship... and it's never been there. And that's bullshit, you know?

Similarly, about her father (and parents more generally):

I look back now and I wish I told him to go and get stuffed. I really do. Because, all those years it was very hard being around them. Everything was focused on death, and dying, and misery...And now (relieved) I am so pleased they're dead. It's gonna sound awful, but I am so frriggin' pleased they're dead! They're gone! This year, it's been this huuuuge burden that's just fallen away, and I've got my old vim and vigour back and I'm working like crazy, and that was about 13 lost years... dealing with those awful people. I'd never realized the amount it took out of... my life, to deal with them. [Jan, aged 50-59, carer to her parents, aged 90-99]

Collectively, these various perspectives demonstrate widespread cultural silences around the diversity of experiences of grief (all the way through to feelings of relief) in bereavement and the imposition, instead, of cultural assumptions about recovery from grief, the stages of this process and the time-delimited nature of bereavement. As a result, these bereaved carers often experienced uncertainty, frustration and anger as their individual experiences jarred with social expectations in their attempts to navigate life after loss and amidst bereavement. 
It was their time: Legitimising death through time

While our participants each knew that the person for whom they provided care was dying (they each were receiving palliative care for conditions with a terminal prognosis), the temporal dimensions of the patients' deaths structured their post-death experiences. These included the age at which the patient died (i.e. time alive), how long they had endured diminished quality of life (i.e. time being ill), and the duration of suffering/rapidity of decline in the patients' health (i.e. time dying). Across these dimensions, we saw a blurring of the boundary between life and death and between relations of care and bereavement, with certain characteristics of the dying process shaping the experience of bereavement that followed. For example, the daughter of one patient who died at the age of 95 recounted how the rightness of the timing of death reduced (though didn't eliminate) the pain of bereavement:

We have our days we're sad and we think about Pop... But we've got those happy memories so there's no sorrow or grief that we can't control. We had our sadness, but we all look at it and it was for the best and we'd had our time with him... Pop was 95 and ... it was just his time, that was Pop's time... We're probably blessed with the time, 95 years is huge. [Claire, aged 50-59, carer to her grandfather, aged 90-99]

Advanced warning of impending death was seen to make bereavement easier too: knowing that death was imminent gave carers time to discuss what was happening, make final amends and say their final farewells. This was seen by some as 'helping' them post-death: 
[W]e were fortunate that we could [talk about death]... and I think that also helped in my... journey afterwards because I felt (clears throat), we had said everything and I didn't, when [patient] passed, I didn't feel that, "I should've said this to him! I should've said that to him!" Everything was said to one another. [Susan, aged 50-59, carer to her husband, aged 60-69]

Of course, the content of end-of-life discussions may vary considerably from instance to instance. What is important to note here is that in the absence of widespread naturally occurring conversations about death (as is the case with persistent death taboos in contemporary Western contexts) advanced notice and time are necessary prerequisites for such conversations to take place, as are the necessary communicative ease and relational closeness. In this case, time for such discussions mitigated against imagined possible regret post-death. In contrast, sudden deaths were imagined to be harder to bear:

A sudden death would probably be a shock and it would probably be a bit longer to get over. We knew from August to December that it was coming. As he got worse and worse we knew it was getting closer and closer... I think we were all preparing for it before it happened. [Henry, aged 50-59, carer to his father, aged $80-89]$

In a related way, uncertainty around the timing of death was experienced as hardship: 
I suppose there was a fair bit of trauma and not really knowing how long mum would live for really... It's a bit distressing, even now. I suppose the hard parts or the difficult parts were not knowing what to expect... I think that was the most difficult part, not knowing. [Sam, aged 60-69, carer to his mother, aged 70-79]

Whereas advanced warning allowed carers to prepare for the death before it happened - in what has been called 'anticipatory grieving' (Fulton et al. 1996, Seale and Addington-Hall 1995, Sweeting and Gilhooly 1990) - uncertainty around the timing of death could preclude grieving until prognostic certainty or death itself was achieved. In many of these instances, grief was still constructed as a linear and timedelimited process where advance warning was seen to confer a head start.

Once death was seen as imminent, carers often saw a rapid final decline as ideal. This was legitimized on the basis of patients not wanting to linger, not wanting death to drag on, and in the hope of reducing suffering:

They said they didn't think Pop would get better and we all knew he wouldn't because he was getting so frail... to tell you the truth, the sooner it happened the better because Pop didn't want to be where he was, not where he was, Pop didn't want to be in the state he was. If he couldn't get better I don't think Pop wanted to be around... He didn't linger and that was the best thing. [Claire, aged 50-59, carer to grandfather, aged 90-99] 
Many participants qualified their admission of hoping for death by emphasizing that experiencing the death of someone for whom they had provided care was still hard:

I've been expecting [patient] to die for 30-something years because he wasn't expected to live ...[but] it's still just really sad, you know? I mean I guess it wasn't a shock but it was still just sad to lose him. [Lisa, aged 50-59, carer to her husband, aged 70-79]

[S]he'd been sick for while we were praying for it almost you know, [but] it's still a horrible experience to go through [Susan, aged 60-69, carer to her mother, aged 80-89]

In these instances, death was welcomed as a release for patients who were thought to have suffered for too long. Although welcoming death generally sits outside of the cultural construction of the 'good death' (Broom et al., 2016), these participants emphasized that it did not diminish the magnitude of their loss, i.e. it was still 'sad' and 'a horrible experience to go through'. In these excerpts, we see points of continuity between the relations of care at the end of life and the experiences of bereavement that follow. In contrast to the culturally dominant picture of 'holding on' to life, and timely 'moving on' after death, we see greater fluidity across the spheres of life and death, which raises a number of questions around people's experiences of relational attachments between the living and the dead.

\section{Discussion:}

In this paper, we have sought to examine how bereavement is experienced by those who have cared for someone who was terminally ill (and received palliative care) and 
who have thus traversed the realms of death, dying and bereavement as they are professionally, interpersonally and culturally construed. The interviews reveal the challenges of negotiating cultural and professional ideas about bereavement, and the everyday practices of accepting, resisting or challenging these constructs. These included wide cultural silences around both the normativities and practicalities of bereavement which left participants with questions and tensions around how to do bereavement, and how to do it right.

This study raises important questions about the enduring and emerging normative pressures towards timely recovery following the death of someone to whom we were close. The participants' accounts, however varied and complex, reveal a kind of tyranny around the temporality ascribed to bereavement and recovery. Certainly, our participants frequently reacted with anger and frustration to perceived societal pressure to grieve and recover in a (timely) fashion that was incongruent with their own personal experiences. What lies beneath such normativities? The answer is likely to be complex. Partly, we would posit a range of mutually exclusive binaries including those of: living/dead, here/gone, grieving/recovered. On one level, this seems entirely logical. Such assumptive bases originate from the biophysical orientation of modernity. As Sociologist Clive Seale, has pointed out, "[o]ur bodies are the means by which we have life, vehicles for our communal sense of what it is to be human. But they also set material limits to our experience, and ultimately dictate that our lives must end" (1998: 11). As such, death, dying and bereavement are arenas in which the assumed divide "between nature and culture is seen in starkly clear terms" (Seale, 1998: 110). Yet, in the everyday of bereavement, such splits are contested, evaded, rejected. This creates considerable problems. Because social ties 
are supposed to end with the death of the embodied self, bereavement, then, requires the timely severing of relational ties with the dead - culturally configured as timely 'moving on'. These prescriptions conceal the reality of bonds beyond living physical presence. What if the bereaved do not wish to cut ties to their beloved? What if recovery is not thought possible by the participant? Or if they have already cut ties before society expects them to? (see also MacArtney et al., 2017).

What might provide a more useful way into the phenomenology of bereavement, as articulated by our participants? Scholars like Merleau-Ponty (1962), for instance, have reworked ideas around individual human embodiment and advanced the related notions of 'intersubjectivity', 'interembodiment' and 'intercorporeality' (see Duranti, 2010; Csordas, 2008; Crossley, 1996; Lupton and Schmied, 2013). The key idea is that embodiment and subjectivity are experienced in relation to other bodies, discourses, spaces, i.e. that embodied subjectivity is less absolutely individual than is commonly assumed. While most of this scholarship focuses on the meaning of relational embodiment between living subjects, McCarthy and Prokhovnik (2014: 22) mobilize similar ideas to account for the persistence of relational connection with a loved one after their death. They introduce the idea of embodied relationally to express how "connectedness is lived out after death in material practices and felt experiences" (McCarthy and Prokhovnik, 2014: 18). On such a view, bereavement need not be bracketed into a delimited window following death, nor situated as a prerequisite to timely 'moving on'.

There is also a considerable problematic evident in the notion of separateness and bereavement (who has died, who has survived). Seale draws on the psychoanalytic 
tradition, notably Freud, to recall that "to love someone is to place in that person a part of one's self, so that when that person dies so does that part of the self' (1998: 193). The approach of embodied relationality - as advanced by McCarthy and Prokhovnik turns this statement on its head: "the embodied relationship with the other does not die with the person, but can be inscribed in the body of the living" (2014: 22). Drawing on the idea of embodied relationality, we suggest that the temporal tensions experienced by bereaved carers (that we have investigated here) might derive from the mismatch between cultural expectations of absolute loss of the other and the individual experience of embodied relationality. On the first model, bereavement is configured as a severing of social bonds with the dead and the accomplishment of timely 'moving on'. In contrast, the approach of embodied relationally allows for greater fluidity of relationships between the living and dead - alleviating some of the temporal tensions experienced by bereaved carers that we've examined here. Of course, how (or whether) on-going affective ties between the living and the dead are maintained remains a question for further qualitative research - to which a longitudinal study design (with multiple interviews over time, post-death) would be well suited. Here was have merely begun to explore some of the affective tensions that emerge at the intersection of normative pressures and lived realities surrounding death, dying and bereavement.

It is worth observing that the idea that relationships with the dead may endure beyond a finite period of bereavement resonates with certain psycho-therapeutic approaches advanced over more recent decades. Such approaches have been developed - often in reaction to the dominance of linear 'stages' models - to account for the 'continuing bonds' with the dead that are often experienced by the bereaved (Klass et al., 2014; 
Klass, 2006; Schuter and Zisook, 1988; Zisook and Sheer, 2009). This approach acknowledges that bereavement is not only a process of separation from the person who died, but also about finding new ways of continuing a relationship with the deceased. Put differently, the both the continuing bonds and embodied relationality approaches find a place for the enduring social presence of the dead, despite their physical absence. Psychiatrists Sidney Zisook and Katherine Shear note: "Bereaved individuals may take some comfort in learning that the relationship does not need to be totally severed, but that it is perfectly acceptable and even normal for the relationship to endure indefinitely" (2009: 68). However, our analysis of the temporal tensions experienced by bereaved carers suggests that the cultural pressures around timely moving on remain strong and that considerable work remains to be done to normalize the idea of indefinitely enduring social ties between the living and the dead.

\section{Acknowledgements}

The authors gratefully acknowledge the interview participants; and the financial support of the Australian Research Council.

\section{Declaration of Competing Interests}

The author(s) declared no potential conflicts of interest with respect to the research, authorship, and/or publication of this article.

\section{Funding}

This research was supported by grants from the Australian Research Council (LP120200268/DP150100414) and an Australian Research Council DECRA Fellowship (DE150100285). 


\section{Notes}

1. For a review of some cross-cultural approaches to grief see (Rosenblatt, 2008).

2. The broader study was focused on pathways to and through palliative care. Within the original study design, a single bereavement-focused interview was deemed appropriate (primarily to avoid over-burdening participants with requests for multiple interviews at a potentially difficult time). The findings and analysis presented here, however, suggest the utility of using multiple post-death interviews to further explore the dynamics of bereavement as they play out across time.

3. Death is not the only social phenomenon that can catalyze feelings of loss and grief - divorce, the loss of a job, forced migration, and miscarriage (among others) may elicit similar cultural scripts regarding 'moving on' (See Papa et al. 2014).

\section{References}

Adam B (1990) Time and social theory. Oxford: Polity.

Bandini J (2015) The medicalization of bereavement: (Ab)normal grief in the DSM5. Death studies, 39(6): 347-52.

Bowlby J (1961) Processes of mourning. International Journal of Psychoanalysis, 4: 317-39.

Broom A, Kirby E, Kenny K, MacArtney J and Good P (2016) Moral ambivalence and informal care for the dying. The Sociological Review 64(4): 987-1004. 
Charmaz K (1990) Discovering' chronic illness: Using grounded theory. Social Science \& Medicine 30(11): 1161-72.

Charmaz K and Milligan MJ (2006) Grief. In Stets JE and Turner JH (eds) Handbook of the sociology of emotions. New York: Springer. pp. 516-43.

Crossley N (1996) Intersubjectivity: The fabric of social becoming. London: Sage.

Csordas TJ (2008) Intersubjectivity and intercorporeality. Subjectivity 22(1): 110-21.

Clark D (2000) Total pain: the work of Cicely Saunders and the hospice movement. American Pain Society Bulletin 10(4): 13-5.

Duranti A (2010) Husserl, intersubjectivity and anthropology. Anthropological Theory 10(1-2): 16-35.

Epstein CF and Kalleberg AL (2001) Time and the sociology of work issues and implications. Work and Occupations 28(1): 5-16.

Faunce WA and Fulton RL (1958) The sociology of death: a neglected area of research? Social Forces 36: 205-09.

Foucault M (1977) Discipline and Punish. New York: Random House. 
Fulton G, Madden C and Minichiello V (1996) The social construction of anticipatory grief. Social Science \& Medicine 43(9): 1349-58.

Giddens A (1991) Modernity and self-identity: Self and society in the late modern age. Stanford: Stanford University Press.

Gillies J and Neimeyer RA (2006) Loss, grief, and the search for significance: Toward a model of meaning reconstruction in bereavement. Journal of Constructivist Psychology 19(1): 31-65.

Glaser BG and Strauss AL (1965) Awareness of Dying. Chicago: Aldine.

Glaser BG and Strauss AL (1968) Time for Dying. Chicago: Aldine

Hall C (2014) Bereavement theory: recent developments in our understanding of grief and bereavement. Bereavement Care, 33(1): 7-12.

Holland JM and Neimeyer RA (2010) An examination of stage theory of grief among individuals bereaved by natural and violent causes OMEGA-Journal of death and dying, 61(2): 103-20.

Horowitz MJ, Siegel B, Holen A, Bonanno GA, Milbrath C and Stinson CH (2003) Diagnostic criteria for complicated grief disorder Focus 1(3): 290-8. 
Hudson PL and Payne S (2009) The future of family caregiving: Research, social policy and clinical practice. In Hudson $\mathrm{P}$ and Payne $\mathrm{S}$ (eds) Family Carers in Palliative Care: A guide for health and social care professionals. Oxford: Oxford University Press, pp. 277-303.

Kellehear A (2007) A social history of dying. Cambridge: Cambridge University Press.

Klass D (2006) Continuing conversation about continuing bonds. Death studies, 30(9): 843-58.

Klass D, Silverman PR and Nickman S (2014) Continuing bonds: New understandings of grief. Washington: Taylor \& Francis.

Kübler-Ross E (1969) On death and dying. London: Tavistock.

Lee RLM (2008) Modernity, Mortality and Re-Enchantment: The Death Taboo Revisited. Sociology 42(4): 745-59.

Lofland L (1985) The Social Shaping of Emotion: The Case of Grief. Symbolic Interaction 8(2): 171-90.

Lupton D and Schmied V (2013) Splitting bodies/selves: women's concepts of embodiment at the moment of birth. Sociology of health \& illness 35(6): 828-41. 
MacArtney J, Broom A, Kirby E, Good P and Wooton J (2017) The liminal and the parallax: living and dying at the end of life. Qualitative Health Research 27(5): 623633.

MacArtney J, Broom A, Kirby E, Good P, Wooton J and Adams J (2016) Locating care at the end of life: burden, vulnerability, and the practical accomplishment of dying. Sociology of Health and Illness 38(3): 479-492.

MacArtney J, Broom A, Kirby E, Good P, Wooton J, Yates P and Adams J (2015) On resilience and acceptance in the transition to palliative care at the end of life. Health 19(3): 263-279.

Merleau-Ponty M (1962) The Phenomenology of Perception. London: Routledge \& Kegan Paul.

Maciejewski PK, Zhang B, Block SD and Prigerson HG (2007) An empirical examination of the stage theory of grief. Journal of the Americal Medical Association 297(7): 716-23.

McAdams DP (2006) The problem of narrative coherence. Journal of Constructivist Psychology 19(2): 109-25.

McCarthy JR and Prokhovnik R (2014) Embodied relationality and caring after death Body \& Society 20(2): 18-43. 
Mills M (2000) Providing Space for Time The Impact of Temporality on Life Course Research. Time \& Society 9(1): 91-127.

Neimeyer RA, Prigerson HG and Davies B (2002) Mourning and meaning. American Behavioral Scientist 46(2): 235-51.

Nowotny H (1994) Time: The modern and postmodern experience. London: John Wiley \& Sons.

Papa A, Lancaster NG and Kahler J (2014) Commonalities in grief responding across bereavement and non-bereavement losses. Journal of affective disorders 161:136-43.

Parkes C (1972) Bereavement: Studies in Grief in Adult Life. London: Tavistock.

Parkes C, Laungani P and Young W (2015) Death and Bereavement Across Cultures: ( $2^{\text {nd }}$ ed) London: Routledge.

Parry JP (1994) Death in Banaras. Cambridge: Cambridge University Press.

Parsons T (1975) The Sick Role and the Role of the Physician Reconsidered The Milbank Memorial Fund Quarterly Health and Society 53(3): 257-78.

Perlow LA (1999) The time famine: Toward a sociology of work time. Administrative science quarterly 44(1): 57-81. 
Pies R (2014) The Bereavement Exclusion and DSM-5: An Update and Commentary. Innovations in Clinical Neuroscience 11(7-8): 19-22.

Ricoer P (1984) Time and Narrative Volume 1. Chicago: University of Chicago Press.

Rosenblatt PC (2008) Grief Across Cultures: A Review and Research Agenda'. In Stroebe MS, Hansson RO, Schut HE, Stroebe WE, and Van den Blink EI (2008) Handbook of bereavement research and practice: Advances in theory and intervention. Washington, DC. American Psychological Association, pp. 207-222.

Saunders CM (1978) The management of terminal malignant disease, 1st ed. London: Edward Arnold.

Shuchter SR and Zisook S (1988) Widowhood. The continuing relationship with the dead spouse. Bulletin of the Menninger Clinic 52, 269-79.

Seale C (1998) Constructing death: The sociology of dying and bereavement. Cambridge: Cambridge University Press.

Seale C and Addington-Hall J (1995) Dying at the best time. Social Science \& Medicine 40(5): 589-95.

Stroebe M and Schut H (1998) Culture and grief. Bereavement Care 17(1): 7-11.

Stroebe M and Schut H (2001) Models of coping with bereavement: A review. In Stroebe M, Hasson R, Stroebe W, Schut, H (eds) Handbook of bereavement research: 
Consequences, coping and Care. Washington DC US: Americal Psychological Association, pp. $375-403$.

Stroebe MS, Hansson RO, Schut HE, Stroebe WE and Van den Blink EI (2008) Handbook of bereavement research and practice: Advances in theory and intervention. Washington, DC: American Psychological Association.

Sweeting HN and Gilhooly MLM (1990) Anticipatory grief: A review. Social Science \& Medicine 30(10): 1073-80.

Thompson EP (1967) Time, work-discipline, and industrial capitalism. Past \& Present 38: 56-97.

Walter T (1995) Natural death and the noble savage. OMEGA-Journal of Death and Dying 30(4): 237-48.

Walter T (1999) On bereavement: The culture of grief. London: McGraw-Hill Education (UK).

Zisook S and Shear K (2009) Grief and bereavement: what psychiatrists need to know. World Psychiatry 8(2): 67-74. 